\title{
Assessing Service Management maturity for the EGI/NGI ecosystem
}

\author{
Owen Appleton ${ }^{1}$ \\ Emergence Tech Limited, gSLM project \\ 19 Ampthill St, Norwich, Norfolk, UK \\ E-mail: owendemergence-tech.com
}

\section{Marcin Radecki}

AGH University of Science and Technology, ACC Cyfronet AGH, PL-Grid

ul. Nawojki 11, 30-950 Kraków, Poland

E-mail: m.radecki@cyfronet.pl

\section{Tomasz Szepieniec}

AGH University of Science and Technology, ACC Cyfronet AGH, gSLM project ul. Nawojki 11, 30-950 Kraków, Poland

E-mail: t.szepieniecleyfronet.pl

This paper introduces a method for assessment of the maturity of IT Service Management (ITSM) practices in federated infrastructures such as National Grid Infrastructures. Effective ITSM is a key factor in sustainability of federated Infrastructures, allowing them to compete with High Performance Computing and commercial Cloud computing services. By understanding service management maturity through use of maturity models and requirements, e-Infrastructure providers can demonstrate not only the need for improvement but also concrete steps that can be taken to make these improvements.

The gSLM project ${ }^{2}$ has built up a Use-Case based model of Grid relationships and used this to define maturity levels with matching requirements for each use case. The resulting requirements can be used as an assessment tool, showing an infrastructures maturity level for each use case. This information can be used to highlight problems, recognize successes and plan improvement in service management. The assessment system was used with PL-Grid, the Polish National Grid Infrastructure, in order to validate and tune the analysis method. The results showed that the system format and number of requirements makes it somewhat time consuming but that it provides valuable data that PL-Grid can use to understand their current service offering and make plans on who to improve it. These experiences will be used for an updated version of the analysis framework.

EGI Community Forum 2012 / EMI Second Technical Conference,

Munich, Germany

26-30 March, 2012

Speaker

The gSLM project is co-funded by the European Commission under contract number 261574 


\section{Introduction}

Federated computing services such as Grid and other e-Infrastructures are increasingly important to scientific and technical research. Some, such as High Performance Computing (HPC), use well-established technologies while other use technical innovations such as Grid computing. The success of these systems and the science they support depends not just on technical factors but also on managerial and organisational factors. Management of computing services that originate from the academic sector, such as Grid computing, sometimes lags behind those of commercial services, as the informal atmosphere in academia does not require them during development. However, as they grow out of academia into broader use, management structures and techniques must be developed.

In the commercial sector IT Service Management (ITSM) is an established discipline that provides structured methods for conceiving, planning and executing effective management of IT services. The gSLM project [1] [2] was established to bring expertise from the commercial ITSM sector to Grids and other federated infrastructures. Experts within gSLM have created an analysis framework that lets Grid Infrastructures be assessed for management maturity, allowing improvements to be planned.

\section{Current situation}

In order to introduce the assessment system this paper presents, it is necessary to explain the current situation with regards to ITSM in Grids and federated infrastructures and prior work on topics such as Service Level Agreement (SLAs).

\subsection{Background}

Federated computing infrastructures, such as Grid computing infrastructures, bring together resources from multiple administrative domains and of different types to provide a combined service. This might be to provide a whole that is greater than the sum of the parts, to cope with geographical and administrative dispersal (perhaps different departments or business units in different countries) or to combine services from multiple providers to give a compound service with specific properties.

These sort of combined services have largely come from the academic sector, developed through informal or semi-formal cooperation between institutions and groups without any concrete, financial or legally binding agreements between them. This environment encourages collaborations and innovation but can lack a drive to formal management of services such as those seen in the commercial sector. A conventional path for new innovations is initiation in a non-commercial sector and development into a more broadly usable product in the commercial sector. However some technologies, such as Grid computing, are at least initially more of use in the academic sector than the commercial one. Commercial Grid computing experienced a brief flourish before being quite quickly replaced by virtualised Cloud computing services. However, Grid computing infrastructures are of use in the academic sphere, notably in computing for the Large Hadron Collider, and as such have developed further in the academic sector than some 
other technologies. However, the lack of commercial involvement has meant that some peripheral aspects of the technology, notably formal service management and well-defined business models, have been neglected.

Now these technologies have grown beyond development and are in daily use by a range of groups and communities. In order to be efficient and sustainable in these contexts they require the knowledge of service management and the development of business models normally carried out by the commercial sector. This paper presents work in this area by the gSLM project, which aims to improve this situation.

\subsection{Prior work}

The gSLM project is not the first group to tackle issues of IT Service Management in Grids and other federated infrastructures. Naturally there have been attempts to find ways to manage services, but they have generally been carried out by teams with IT rather than service management expertise. This is reasonable given the profile of Grid computing experts, but has lead to solutions based on a bottom up, technical approach to service management. The results have focussed on Service Level Management (SLM), one aspect of ITSM concerned with SLAs and other formal agreements to define the content and warranty of services. Examples include the SLAs in Grids Workshop, which tends to attract papers on topics such as the WSAgreement standard [3] [4] and machine-readable SLAs [5].

While SLM and SLAs are important aspects of ITSM, they form only one small part of ITSM as a whole. To provide an example, in perhaps the commonest framework for ITSM, ITIL (The IT Infrastructure Library), SLM as a whole comprises one of 26 processes, and SLAs are not the only elements in SLM. SLAs remain a very important topic, and may often be the first element of ITSM that organisations feel the need to address, but improvement here is of limited use unless other ITSM processes support it. For instance, an SLA may set out the standard of service, such as uptime, along with a set of steps to be taken when this is not achieved, and concomitant penalties for failing to supply the agreed upon service. However, if the service is not well defined through a set of service strategy processes, and if there are no definitions of the operational processes such as incident management to cope with service failures, the SLA cannot fulfil its function. The gSLM project works to take SLM beyond SLAs and also to bring in necessary elements of ITSM.

The work presented here does not seek to replace existing work, rather to augment and support it to make it of more use. For instance, there is a body of work related to SLA-based scheduling on Grid Infrastructures, but this assumes the prior existence of a method for defining services, offering them in a service catalogue and then signing an SLA with a customer. The SLA may well and probably should contain technical aspects that allow for job scheduling, but SLAs need to go beyond this and capture more than technical service parameters. They need to define the details of a provider/customer relationship and, for instance, represent a shared understanding of a service such that a positive working relationship can be attained. Furthermore, broader SLM and ITSM structures would support the use of SLAs and, for instance, SLA based scheduling. It would also make Grid computing more compatible with commercial competitors by adopting the same standards and framework for managing services 
that they use. This could help lessen the false impression that academically derived services fit a stereotype of 'nice idea, shame about the implementation'.

\section{Assessment framework}

Here we present a framework for assessing the maturity of service management in a Grid Infrastructure. While Grid-focussed, the basic structure also has relevance to other federated infrastructures. However, one major challenge in bringing commercial ITSM to an academic context is that the ITSM vocabulary is abstract and resembles 'management speak' which has a dubious reputation amongst academics. Hence the framework presented here is intended to use a vocabulary that will be familiar to Grid practitioners. However, the model could equally apply to a federated Cloud or data infrastructure, and indeed the gSLM project intended to provide a more neutral flavour of the framework in later outputs.

\subsection{Why assessment?}

The authors of this paper are engaged in a project that seeks to improve Grid service management, in particular service level management. The challenge this presents is twofold; first to understand how to make use of experience from commercial ITSM in the Grid context and second to make this knowledge palatable to Grid practitioners. Based on discussions with experts from both the Grid and ITSM fields, it was decided that several problems presented themselves. First, the Grid ecosystem has structural features that are unlike commercial service provision scenarios, but also the Grid ecosystem is heterogeneous and perhaps chaotic with respect to the relationships between users, providers, federators, resource owners, regulators and funding bodies. A first step in trying to improve Grid service management was to come up with a model of the community and the relationships between actors, a use case model, that was close enough to current reality to be obviously applicable to practitioners but also simple enough to serve as a basis for a more rational set of management processes than is currently possible.

A secondary challenge in improving Grid SLM is to reduce the impression that improvement means 'throw away everything you do and implement ITIL' or another commercially popular framework. This challenge is actually also seen in introducing ITSM in commercial contexts, but more difficult on the Grid as not only do systems like ITIL seem to imply massive changes but they also clearly refer to a culture and organisational structure that the academic sector lacks. To mitigate these challenges, we propose the use of assessment as a way to promote and encourage improvement. By presenting practitioners with a set of questions they can easily answer, using familiar vocabulary and based on concepts they use regularly, we can gather data on ITSM maturity relatively painlessly. Once data is collected we can map it to maturity levels for each relationship in our model of the Grid ecosystem. This gives a 'score' for maturity in different areas, but also shows the 'delta' to improve to a higher level of maturity. This supports a model of incremental improvement of ITSM rather than a 'big bang' model where everything changes immediately. Through showing how real experience maps to ITSM 
maturity, and showing how incremental change can be used to improve service management, we hope to make ITSM techniques approachable and achievable for Grid Infrastructures.

\subsection{Use case model}

The first step in this process is to define a model of the community that encompasses a sufficient set of situations. We propose the following actor model:

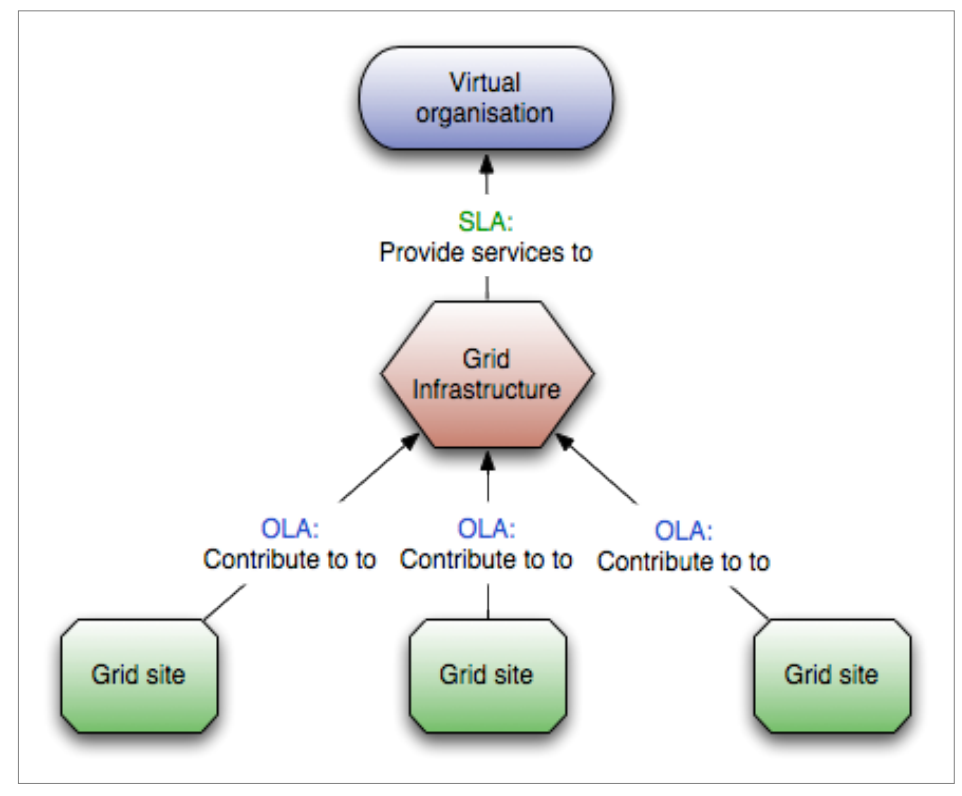

Figure 1: gSLM actor model

Figure 1 encompasses most Grid relationships with only three basic actor types. We define these below:

Virtual Organisation (VO): A grouping of individual users that come together for some purpose. This might be a group of users in the same subject area, or in the same geographical location of who are grouped around some other axis. Virtual Research Communities could also be considered a VO in this sense.

Site: A single organisation that owns or exercises unitary control over a set of computing resources. This might be a University computing centre, a standalone High Performance Computing centre or a commercial data centre. In a Grid context this site should also offer one or more Grid services.

Grid Infrastructure (GI): A body or organisation that federates resources from two or more resource coordinators into a single customer facing service. They might federate sites, or alternatively could federate smaller GIs (who themselves federate sites). A GI is a Grid service provider that makes agreements with VOs to provide the services they federate.

With these actors in place we define a set of Use Cases - the smallest management activities that can be carried out atomically. Each use case applies to a set of actors and relevant 
duties and interactions. Use cases are further defined as a set of steps to be carried out to achieve a change in the state of the world.

We define the use cases in two groups. The first group comprises those related to Service Level Management (SLM) - as the primary goal of the gSLM project. These are further divided into SLA based use cases (relating to agreements with users) and Operational Level Agreement (OLA) based use cases (relating to agreements with suppliers). The second group comprises activities from other areas of IT Service Management that serve to support SLM activities, so called Service Delivery Management related use cases. These uses cases are presented in Table 1 in the annex to this paper. These use cases cover a sufficient percentage of the activities related to SLM and ITSM to be of use in improving ITSM while remaining lightweight enough to be implemented. Each use case has the elements seen in Table 2 in the annex to this paper as well as a more detailed sequence of steps to carry out.

\subsection{Maturity models}

With the Use Case model defining the relationships and actions making up SLM and ITSM activities in a Grid Infrastructure we can now look at how these use cases will appear at different levels of maturity.

In order to create a maturity model we take input from maturity models in the commercial sector, where they are a common tool to define levels of maturity in many activities. The bestknown example is probably the Capability Maturity Model Integration (CMMI). The general scheme of CMMI is shown below.

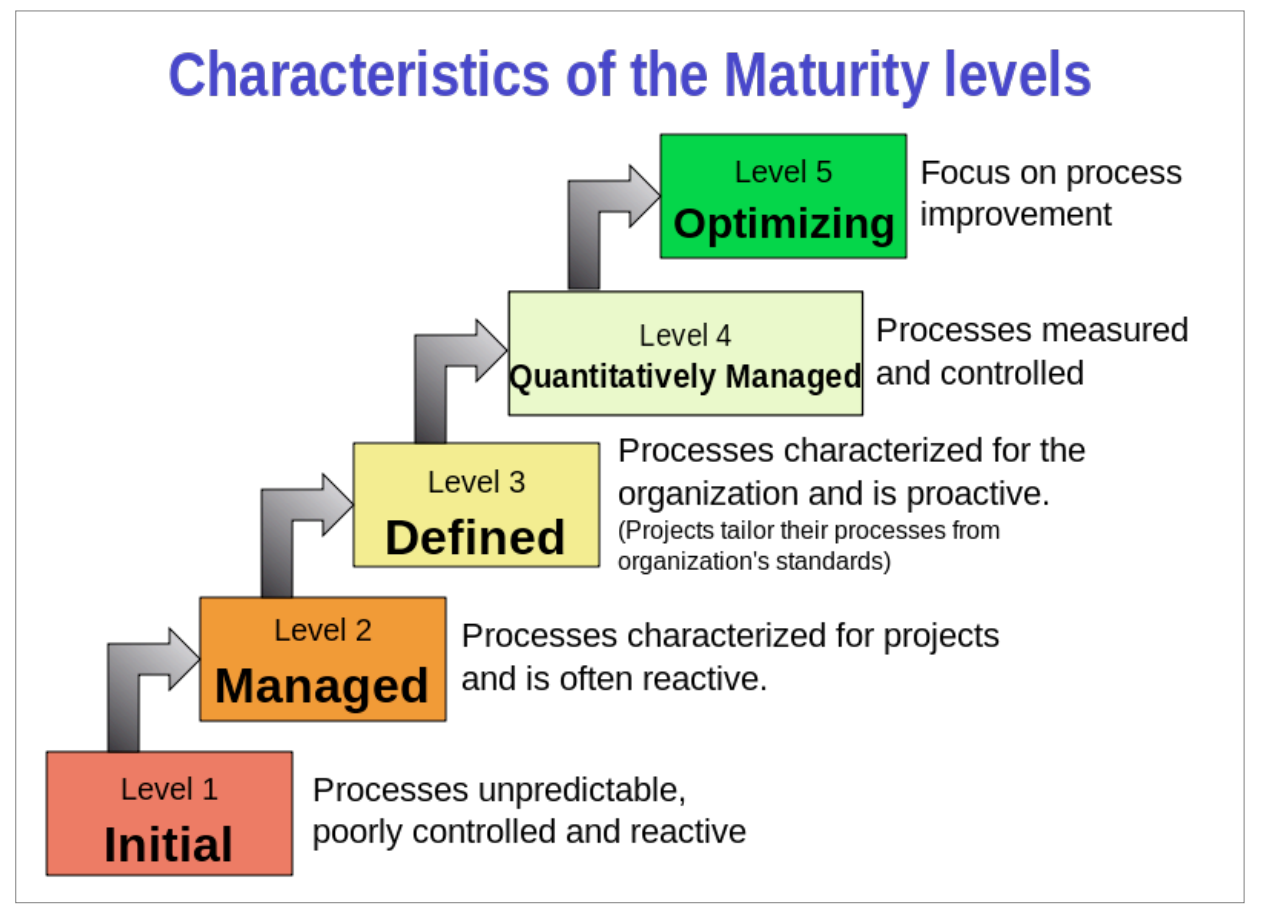

Figure 2- The five process maturity levels in the Capability Maturity Model [6]. 
Maturity models also feature in many ITSM frameworks and methodologies. We take our general model from the COBIT framework [7] on IT management and governance, interpreting its levels to provide a descriptive general maturity model. With the following levels:

- Level 0 - Non-existent

- Level 1 - Initial/Ad-hoc

- Level 2 - Repeatable but intuitive

- Level 3 - Defined

- Level 4 - Managed and Measurable

- Level 5 - Optimised

The full descriptive maturity model is available online. [8] We then describe these maturity levels for each use case, and example in Table 3 in the annex to this paper.

\subsection{Requirements engineering}

Having defined use cases and maturity levels, we next look at what each use case maturity level looks like in a practical situation. To define this we have set out a set of requirements for each use case maturity level. These represent the concrete systems and policies in place to support ITSM, as shown in Table 4 in the annex to this paper, which shows Level 1 requirements for a single use case:

Having defined a set of requirements (181 for the first stage, SLM use cases), these were catalogued and compared to remove duplicates and categorise them in a rational manner. The result of this is a data set that progresses from use cases to maturity levels and matching requirements.

\subsection{Requirements based assessment}

Having created these three connected sets of data, use cases, maturity levels and requirements, we can use them in reverse to carry out analysis of Grid Infrastructures. We reformat the requirements list into a set of questions that can be asked of Grid Infrastructures, each with a yes/no answer. From this set of results we can calculate at which maturity level a Grid Infrastructure is operating for each use case. We have created an initial beta online analysis tool of this type using an online survey tool, where Grid Infrastructure representatives can answer a list of requirement questions. These are then entered into a spread sheet document that provides instant analysis of the results, and that can be used for self-assessment or as a basis for consultation with experts to improve ITSM.

\subsection{Results analysis}

The results of requirements based analysis can be used in various ways. First they provide a quick way to show the maturity of an Infrastructure in a partially quantitative manner. We can look at the spread of use cases maturity levels, noting various averages to give an idea of where 
an Infrastructure stands. Beyond this we can look at in what areas an infrastructure has higher and lower use case maturity levels - showing in what areas the infrastructure is being more and less successful in managing the services they offer. This can also catalyse discussion of which use cases are more and less relevant to a particular Infrastructure, helping with strategic planning of current and future management activities.

The results from this analysis can also be used to plan improvements to ITSM in a realistic and cost effective way. For instance they can identify missing requirements that will quickly raise the ITSM maturity level of use cases - filling in the missing links and making sure infrastructures benefit from the work they have already carried out. Alternatively, once areas for improvement have been identified, the related requirements will give a set of concrete tasks to be carried out, rather than more abstract management goals that might be harder to understand or convince staff of the value of.

In all these ways, the results help make IT Service Management a challenge that can be reasonably and incrementally faced in grid Infrastructures.

\section{Validation: PL-Grid Assessment}

In order to validate the results, we have tested them with an initial subject, PL-Grid, the Polish National Grid Infrastructure. PL-Grid is coordinated by Cyfronet, a partner in the gSLM project, and as an organisation are actively engaged with ITSM [10]. We present the results of the initial assessment here (using only the first stage, SLM use cases) both as a validation of the assessment method and as a vehicle to explain its value.

PL-Grid filled in the beta online survey with some assistance from gSLM members (largely around terminology) and was presented with the initial results, which were discussed between PL-Grid and gSLM team members.

\subsection{Introduction to SLM in PL-Grid}

The PL-Grid Infrastructure is being build by a consortium composed of the five largest compute centres in Poland. The consortium is funded by the Ministry of Science and Higher Education through subsidies for research and development programmes. Customers of the infrastructure are recruited from Polish scientists and colleagues with whom they are working on their research topics. The conditions for providing resources are the subject of Service Level Agreements, which are signed between groups of users (VOs) and PL-Grid (as the GI).

The process of signing SLAs between VOs and the infrastructure is on-line and makes use of a web-based tool called Bazaar [11] where users can specify SLA parameters such as amounts of compute time, storage and the time period they are requested for. Such agreements are also referred as "compute grants". Multiple sites can provide resources required for a single SLA, and as such each SLA is underpinned by a number of internal agreements between PL-Grid and sites called OLAs. As a result, PL-Grid OLAs are always related to some customer facing SLA. 
As PL-Grid is part of the European Grid Infrastructure (EGI) there are also EGI OLAs signed between Sites and PL-Grid. These OLAs specify general service levels for a site to be certified for the PL-Grid/EGI infrastructure. PL-Grid OLAs may raise service levels for specific customer above the threshold defined in the EGI OLAs.

The SLM toolbox used in PL-Grid also contains a monitoring system that collects accounting data related to compute grants from all sites. This data is necessary to track fulfilment of SLA and OLA parameters. Based on this data it is possible to send violation notifications and early warnings.

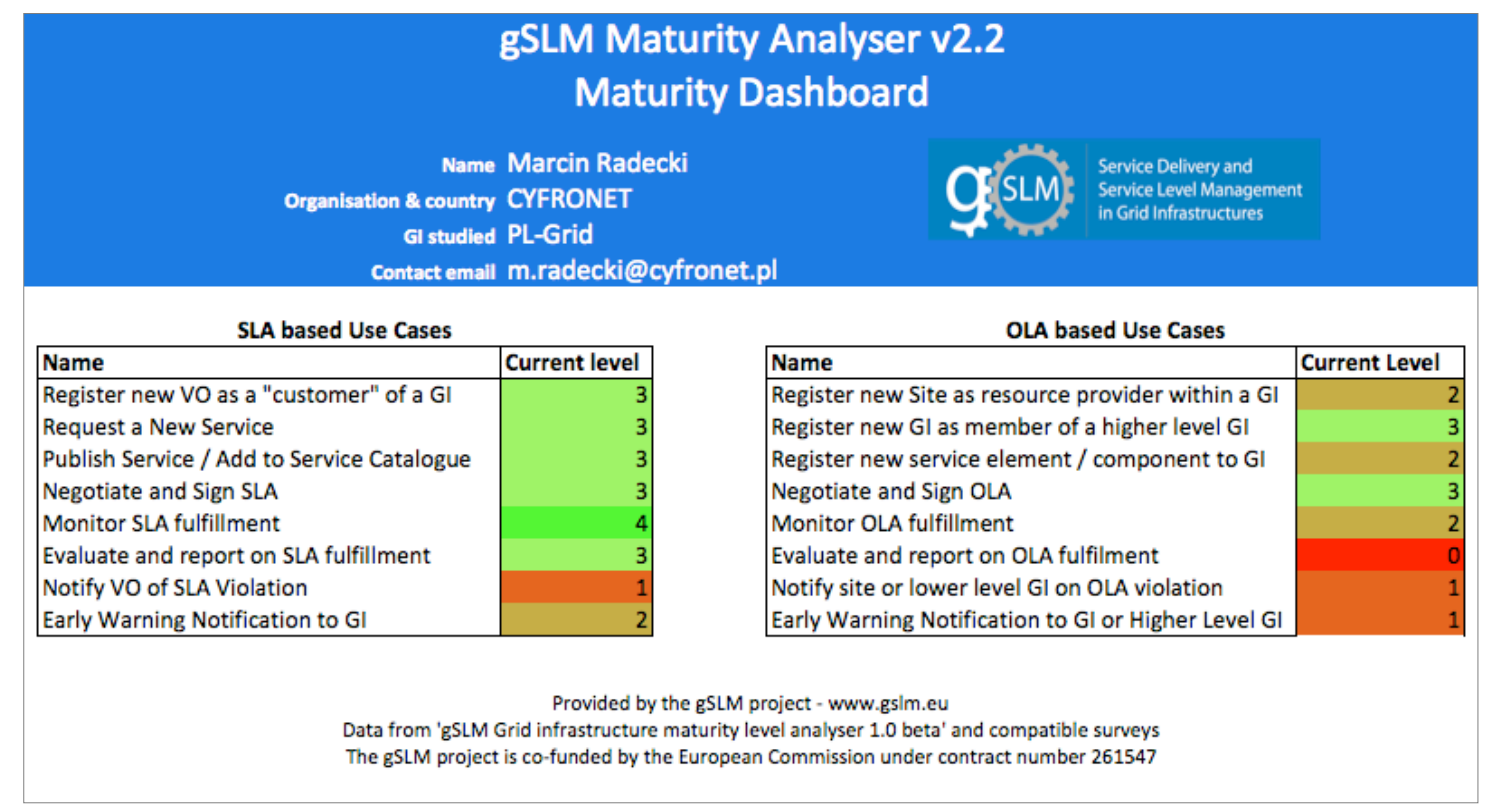

Figure 3-gSLM Maturity Dashboard, assessment of PL-Grid

\subsection{Initial results and use case relevancy}

The first analysis of the results involved looking at what was the current maturity level for each use case in the PL-Grid Infrastructure. This was calculated by taking the highest level for which all requirements in that and lower levels were met. The initial results are shown in Figure 3 .

We can also show the spread of use cases, as shown below in Figure 4. From these results we can immediately make some general statements abut PL-Grid's ITSM maturity. We can see from Figure 4 that the most common maturity level is ' 3 : Defined', and that three quarters of use cases are at level '2:Repeatable but Intuitive' or above. This matches the informal impression within PL-Grid on their level of maturity, and also fits with their efforts in the last two years to improve and formalize ITSM practices. This has lead to a situation where tools and procedures cover basic processes, such as VO registration, though they can still be improved.

We can also provide more full results of the breakdown of how many requirements have been met at each use case maturity level. This can be seen in Figure 5. 


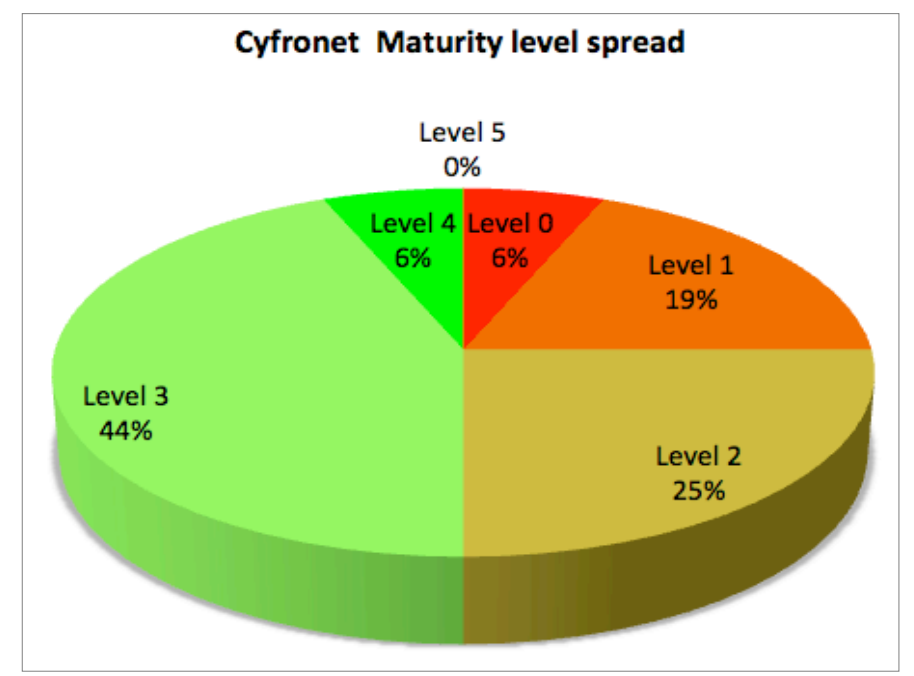

Figure 4 - Maturity Level Spread, assessment of PL-Grid.

\subsection{Broad results and use case relevancy}

We can also make some initial statements about the places where PL-Grid is more successful in ITSM. Figure 5 shows that in general, PL-Grid is more mature in SLA based use cases than OLA based use cases - which implies they are more mature in their relations with users than their relations with sites or other resource providers. In discussion with PL-Grid this is actually an intentional 'tilt' towards users, based on the priorities of the organization. In their specific situation, PL-Grid have very strong ties to their sites, which means that they can operate adequately without formalized SLM in their OLA related use cases. In comparison they are keen to make a strong service offering to users, so have invested more effort in setting up userorientated systems (represented in SLA related use cases). This is also important as to justify their on-going funding it is important that they are able to report their successes in supporting a wide range of research groups and topics to their national authorities. Stronger SLA based ITSM processes not only improve their work in supporting user groups but also provide monitoring and measurement systems that make it easier for them to report the successes they have. This is also useful feedback for the gSLM project, as it presents a way in which the assessment framework and improving ITSM is in the interest of Grid Infrastructures.

It is also positive that the assessment results catalyse discussion of which areas of ITSM are more and less immediately relevant to a Grid Infrastructure, and how improving ITSM can serve larger strategic goals of an organization. In the case of PL-Grid, further discussions went into the relevancy and priority of various use cases. An example of this is seen in use cases 15 and 16. Use Case 15 covers notification of sites of a violation of the Operational Level Agreement between the GI and site. In comparison Use Case 16 covers a way for sites to notify GIs of possible or known future violations of OLAs. These are shown in Figure 6 - Comparison of the relevance and priority of use cases in PL-Grid. In both cases at present PL-Grid is at maturity level 1, though in Use Case 15 they have met two out of three requirements to go to level 2. In discussion with PL-Grid it became apparent that there is both a form of dependency between these use cases and also a disparity in the effort required to improve their maturity. 
Figure 5-gSLM Maturity Analyser, assessment of PL-Grid

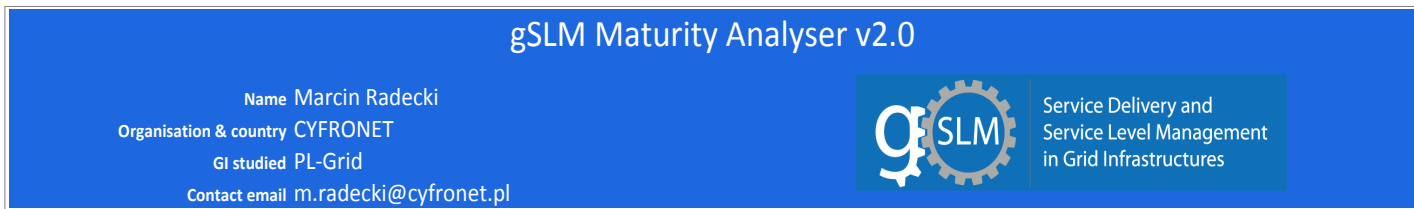

Key: The analyser shows your maturity by showing how many requirements you meet for each use case at each maturity level

= All requirements met

= Half or more requirements met

= less than half requirements met

\section{SLA related Use Cases}

\begin{tabular}{|c|c|c|c|}
\hline Use case 1: UCs:SLM:SLA:REG & Register new & VO as a "custor & mer" of a GI \\
\hline Maturity level Requirements Passed & $\begin{array}{l}\text { Total } \\
\text { requirements }\end{array}$ & $\begin{array}{l}\% \text { Complete for } \\
\text { maturity level }\end{array}$ & Maturity level \\
\hline Level 1 & & 20 & 0 Level 1 \\
\hline Level 2 & & 10 & 0 Level 2 \\
\hline Level 3 & & 20 & 0 Level 3 \\
\hline Level 4 & & 20 & 0 Level 4 \\
\hline Level 5 & & 20 & 0 Level 5 \\
\hline
\end{tabular}

\begin{tabular}{|c|c|c|c|}
\hline \multirow{2}{*}{ Maturity level Requirements Passed } & \multicolumn{3}{|c|}{ Request a New Service } \\
\hline & $\begin{array}{l}\text { Total } \\
\text { requirements }\end{array}$ & $\begin{array}{l}\text { \% Complete for } \\
\text { maturity level }\end{array}$ & Maturity level \\
\hline Level 1 & 2 & $20 \quad 100$ & 0 Level 1 \\
\hline Level 2 & 2 & 20 & 0 Level 2 \\
\hline Level 3 & 3 & 30 & 0 Level 3 \\
\hline Level 4 & 2 & $3 \odot 66.66666667$ & 7 Level 4 \\
\hline Level 5 & 1 & 10 & 0 Level 5 \\
\hline
\end{tabular}

\begin{tabular}{|c|c|c|c|}
\hline \multirow{2}{*}{$\begin{array}{l}\text { Use case 3: UCs:SLM:SLA:PUB } \\
\text { Maturity level Requirements Passed }\end{array}$} & \multicolumn{3}{|c|}{ Publish Service / Add to Service Catalogue } \\
\hline & $\begin{array}{l}\text { Total } \\
\text { requirements }\end{array}$ & $\begin{array}{l}\text { \% Complete for } \\
\text { maturity level }\end{array}$ & or Maturity level \\
\hline Level 1 & 1 & 10 & to0 Level 1 \\
\hline Level 2 & 2 & 20 & 100 Level 2 \\
\hline Level 3 & 2 & 20 & 100 Level 3 \\
\hline Level 4 & 0 & $2 \otimes$ & 0 Level 4 \\
\hline Level 5 & 1 & 20 & 50 Level 5 \\
\hline
\end{tabular}

\begin{tabular}{|c|c|c|c|}
\hline \multicolumn{4}{|c|}{ Use case 4: UCs:SLM:SLA:NEG Negotiate and Sign SLA } \\
\hline & Total & $\%$ Complete for & \\
\hline Maturity level Requirements Passed & d requirements & maturity level & Maturity level \\
\hline Level 1 & 2 & $20 \quad 100$ & 0 Level 1 \\
\hline Level 2 & 1 & 10 & 0 Level 2 \\
\hline Level 3 & 4 & 40 & 0 Level 3 \\
\hline Level 4 & 2 & $3 \odot 66.66666667$ & 7 Level 4 \\
\hline Level 5 & 1 & 20 & 0 Level 5 \\
\hline
\end{tabular}

\begin{tabular}{|c|c|c|c|c|}
\hline \multicolumn{5}{|c|}{ Use case 5: UCs:SLM:SLA:MON Monitor SLA fulfillment } \\
\hline \multirow{2}{*}{\multicolumn{2}{|c|}{$\begin{array}{ll}\text { Total } \\
\text { Maturity level Requirements Passed } & \text { requirements }\end{array}$}} & \multirow{2}{*}{\multicolumn{2}{|c|}{$\begin{array}{l}\% \text { Complete for } \\
\text { maturity level }\end{array}$}} & \\
\hline & & & & Maturity level \\
\hline Level 1 & 1 & 10 & & Level 1 \\
\hline Level 2 & 1 & 10 & & Level 2 \\
\hline Level 3 & 2 & 20 & & Level 3 \\
\hline Level 4 & 1 & 10 & & Level 4 \\
\hline Level 5 & 0 & $1 \otimes$ & & Level 5 \\
\hline
\end{tabular}

\begin{tabular}{|c|c|c|c|}
\hline \multirow[t]{2}{*}{ Use case 6: UCs:SLM:SLA:EVR } & \multicolumn{3}{|c|}{ Evaluate and report on SLA fulfillment } \\
\hline & $\begin{array}{l}\text { Total } \\
\text { requirements }\end{array}$ & $\begin{array}{l}\text { \% Complete for } \\
\text { maturity level }\end{array}$ & Maturity level \\
\hline Level 1 & & 20 & 0 Level 1 \\
\hline Level 2 & & 30 & 0 Level 2 \\
\hline Level 3 & & 20 & 0 Level 3 \\
\hline Level 4 & & $3 \otimes 33.3333333=$ & 3 Level 4 \\
\hline Level 5 & & $2 \otimes$ & 0 Level 5 \\
\hline
\end{tabular}

\begin{tabular}{|c|c|c|c|}
\hline Use case 7: UCs:SLM:SLA:NFY & Notify VO of & SLA Violation & \\
\hline Maturity level Requirements Passed & $\begin{array}{l}\text { Total } \\
\text { requirements }\end{array}$ & $\begin{array}{l}\text { \% Complete for } \\
\text { maturity level }\end{array}$ & Maturity level \\
\hline Level 1 & 5 & 50 & 0 Level 1 \\
\hline Level 2 & 2 & $3 \bigcirc 66.66666667$ & 7 Level 2 \\
\hline Level 3 & & 40 & 0 Level 3 \\
\hline Level 4 & & $3 \otimes$ & 0 Level 4 \\
\hline Level 5 & 0 & 10 & 0 Level 5 \\
\hline
\end{tabular}

\begin{tabular}{|c|c|c|c|}
\hline \multicolumn{4}{|c|}{ Use case 8: UCs:SLM:SLA:EWR Early Warning Notification to GI } \\
\hline Maturity level & $\begin{array}{l}\text { Total } \\
\text { ed requirements }\end{array}$ & $\begin{array}{l}\text { \% Complete for } \\
\text { maturity level }\end{array}$ & r Maturity level \\
\hline Level 1 & 3 & 30 & 00 Level 1 \\
\hline Level 2 & 1 & 10 & Do Level 2 \\
\hline Level 3 & 2 & $3 \odot 66.6666666$ & 57 Level 3 \\
\hline Level 4 & 0 & $3 \otimes$ & 0 Level 4 \\
\hline Level 5 & 0 & $3 \otimes$ & 0 Level 5 \\
\hline
\end{tabular}

Provided by the gSLM project - www.gslm.eu

Data from ' $\mathrm{SSLM}$ Grid infrastructure maturity level analyser 1.0 beta' and compatible surveys The gSLM project is co-funded by the European Commission under contract number 261547

\section{OLA related Use Cases}

\begin{tabular}{|c|c|c|}
\hline Use case 9: UCs:SLM:OLA:RGS & Register new & w Site as resource provider within a GI \\
\hline & $\begin{array}{l}\text { Total } \\
\text { requirements }\end{array}$ & $\begin{array}{l}\text { \% Complete for Maturity } \\
\text { maturity level level }\end{array}$ \\
\hline Level 1 & & $50 \quad 100$ Level 1 \\
\hline Level 2 & & 100 Level 2 \\
\hline Level 3 & & 80 Level 3 \\
\hline Level 4 & & 50 Level 4 \\
\hline Level 5 & & 75 Level 5 \\
\hline
\end{tabular}

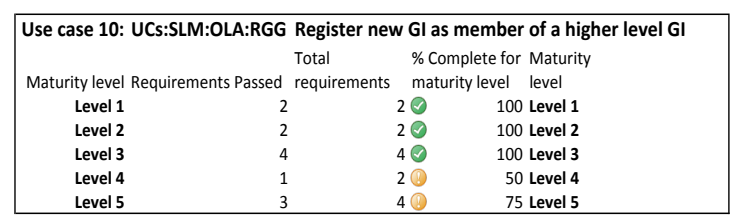

\begin{tabular}{|c|c|c|}
\hline Use case 11: UCs:SLM:OLA:RGE & E Register new & service element / component to $G$ \\
\hline Maturity level Requirements Passed & $\begin{array}{l}\text { Total } \\
\text { d requirements }\end{array}$ & $\begin{array}{l}\text { \% Complete for Maturity } \\
\text { maturity level level }\end{array}$ \\
\hline Level 1 & $3 \quad 3$ & $30 \quad 100$ Level 1 \\
\hline Level 2 & 3 & 100 Level 2 \\
\hline Level 3 & 3 & 3 (1) 66.6666667 Level 3 \\
\hline Level 4 & 1 & 50 Level 4 \\
\hline Level 5 & 4 & 100 Level 5 \\
\hline
\end{tabular}

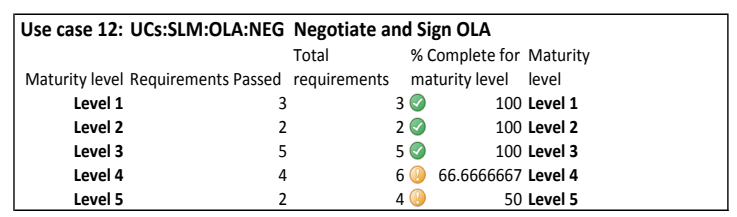

\begin{tabular}{|c|c|c|}
\hline \multicolumn{3}{|c|}{ Use case 13: UCs:SLM:OLA:MON Monitor OLA fulfillment } \\
\hline & Total & $\%$ Complete for Maturity \\
\hline \multirow{2}{*}{\multicolumn{3}{|c|}{$\begin{array}{l}\text { Maturity level Requirements Passed requirements maturity level level } \\
\text { Level } 1\end{array}$}} \\
\hline & & \\
\hline Level 2 & 20 & 100 Level 2 \\
\hline Level 3 & $4(1)$ & 75 Level 3 \\
\hline Level 4 & $2 \otimes$ & 0 Level 4 \\
\hline Level 5 & $2 \otimes$ & 0 Level 5 \\
\hline
\end{tabular}

\begin{tabular}{|c|c|c|}
\hline Use case 14: UCs:SLM:OLA:EVR & Evaluate and & $\mathrm{d}$ report on OLA fulfilment \\
\hline Maturity level Requirements Passed & $\begin{array}{l}\text { Total } \\
\text { requirements }\end{array}$ & $\begin{array}{l}\text { \% Complete for Maturity } \\
\text { maturity level level }\end{array}$ \\
\hline Level 1 & & 6 66.6666667 Level 1 \\
\hline Level 2 & & $3 \otimes 33.3333333$ Level 2 \\
\hline Level 3 & & 0 Level 3 \\
\hline Level 4 & & 0 Level 4 \\
\hline Level 5 & & 0 Level 5 \\
\hline
\end{tabular}

\begin{tabular}{|c|c|}
\hline Use case 15: UCs:SLM:OLA:NFY & Notify site or lower level GI on OLA violation \\
\hline & $\begin{array}{ll}\text { Total } & \% \text { Complete for Maturity } \\
\text { requirements } & \text { maturity level level }\end{array}$ \\
\hline $\begin{array}{l}\text { Maturity level Requirements Passed } \mathrm{r} \\
\quad \text { Level } 1\end{array}$ & $\begin{array}{l}\text { requirements } \\
50\end{array}$ \\
\hline Level 2 & 3 3) 66.6666667 Level 2 \\
\hline Level 3 & 40 Level 3 \\
\hline Level 4 & 0 Level 4 \\
\hline Level 5 & 0 Level 5 \\
\hline
\end{tabular}

\begin{tabular}{|c|c|c|}
\hline \multirow[t]{2}{*}{ Use case 16: UCs:SLM:SLA:EWR } & \multicolumn{2}{|c|}{ Early Warning Notification to GI or Higher Level GI } \\
\hline & Total & \% Complete for Maturity \\
\hline Level 1 & 5 & 100 Level 1 \\
\hline Level 2 & 1 & 0 Level 2 \\
\hline Level 3 & 3 & 33.3333333 Level 3 \\
\hline Level 4 & 3 & 0 Level 4 \\
\hline Level 5 & 3 & 0 Level 5 \\
\hline
\end{tabular}


It does not make sense to invest effort in an early warning schema for sites to notify GIs of possible future violations (Use Case 16) if you cannot notice from the GI point of view that an OLA violation has occurred and notify the site of it (Use Case 15). Furthermore. PL-Grid point out that OLA violation notification is in principle a mechanical task. OLAs can be largely automatically monitored, and in either case can the notification can be an automatic and mechanistic system. In comparison, early warning forecasting and notification is a far more complex process that requires analysis of a broad range of technical and non-technical factors, from the reliability of the power systems at a data centre to forthcoming software releases or staff sickness. Clearly assigning equal effort to these two Use Cases does not make sense for PL-Grid, and in general it is better to improve OLA violation notification before tackling early warning forecasting, though both must be faced eventually. PL-Grid suggested for instance that once they reach maturity level 4: Managed and Measurable in Use Case 15 then would look at improving the maturity of Use Case 16. Again, the assessment assists PL-Grid in planning and prioritizing future improvements.

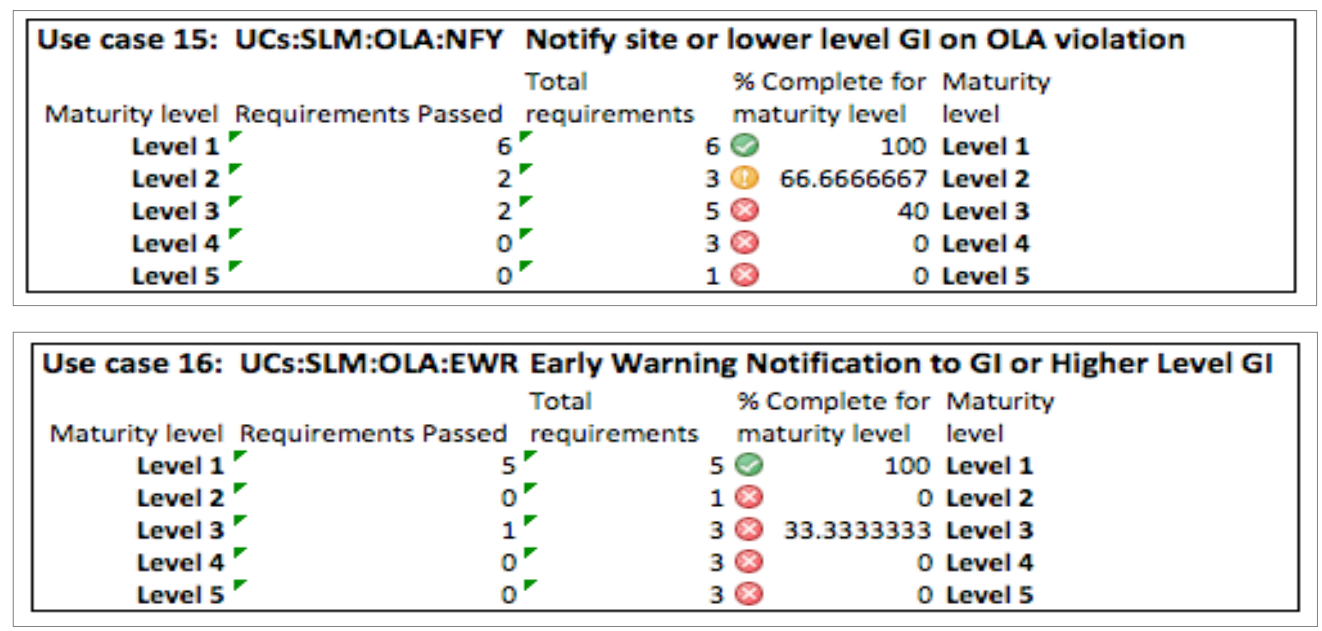

Figure 6-Comparison of the relevance and priority of use cases in PL-Grid.

\subsection{Quick wins}

Drawing on a concept from the ITIL best practice framework, gSLM advocates looking for 'quick wins' that can be achieved in maturity levels by fulfilling small numbers of requirements. These might be single missing requirements that allow a jump to a higher maturity level, or perhaps use cases that are low maturity and drag down the impact of better maturity in several others use cases. In the latter example we can look at the general level of he SLA-related use cases. Looking at Figure 3, we can see that Use Cases 7 and 8 are the lowest in the SLA related Use Case area, and may be reducing the general level of maturity when dealing with users. Looking in more detail at Use Case 7, Notify VO of SLA Violation (see Figure 8 below) we can see that while only at Level 1, PL-Grid has achieved two out of three requirements for Level 2, and two out of four for Level 3. As a result, by fulfilling three additional requirements PL-Grid can improve maturity by two levels. After this PL-Grid could 
look at improving Use Case 8: Early Warning Notification to GI (See Figure 8 below), where only one requirements needs to be fulfilled to reach maturity Level 3 .

\begin{tabular}{|c|c|c|c|c|}
\hline \multirow{2}{*}{$\begin{array}{l}\text { Use case 2: UCs:SLM:SLA:REQ } \\
\text { Maturity level Requirements Passed }\end{array}$} & \multicolumn{4}{|c|}{ Request a New Service } \\
\hline & $\begin{array}{l}\text { Total } \\
\text { requirements }\end{array}$ & & for & Maturity level \\
\hline Level 1 & & 20 & 100 & Level 1 \\
\hline Level 2 & & 20 & 100 & Level 2 \\
\hline Level 3 & & 30 & 100 & Level 3 \\
\hline Level 4 & & 3 & 6667 & Level 4 \\
\hline Level 5 & 1 & 10 & 100 & Level 5 \\
\hline
\end{tabular}

Figure 7 - Quick wins - filling missing requirements

The other area of looking for quick wins is illustrated in Use Case 2: Request a new Service (See Figure 7). Here PL-Grid are currently at Level 3, but looking at the details we can see that they have already achieved all of Level 5 and are missing only one requirement for Level 4. This means fulfilling a single requirement brings this Use Case to maximum maturity within the gSLM schema. Using the analysis document we can see that the missing requirement is R16: GI guarantees to answer service requests in defined time. Speaking to PL-Grid it seems that in fact there is already a defined time internally at PL-Grid for fulfilling service requests, but this timescale is not actually provided to VOs in the SLA. It is a very minor change to add the deadline to the SLA, improving the service provided to VOs for almost no effort on the part of PL-Grid. Such quick wins can be quickly identified using the gSLM assessment framework.

\begin{tabular}{|c|c|c|c|}
\hline \multirow{2}{*}{$\begin{array}{l}\text { Use case 7: UCs:SLM:SLA:NFY } \\
\text { Maturity level Requirements Passed }\end{array}$} & \multicolumn{3}{|c|}{ Notify VO of SLA Violation } \\
\hline & $\begin{array}{l}\text { Total } \\
\text { requirements }\end{array}$ & $\begin{array}{l}\% \text { Complete for } \\
\text { maturity level }\end{array}$ & Maturity level \\
\hline Level 1 & - & $5 \odot \quad 100$ & Level 1 \\
\hline Level $2^{r}$ & 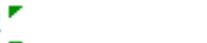 & $3 \bigcirc 66.66666667$ & Level 2 \\
\hline Level $3^{\mathbf{r}}$ & 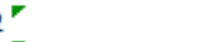 & $4(1) \quad 50$ & Level 3 \\
\hline Level 4 & 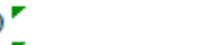 & $3 \otimes$ & Level 4 \\
\hline Level $5^{\mathbf{}}$ & 5 & 10 & Level 5 \\
\hline
\end{tabular}

\begin{tabular}{|c|c|c|c|}
\hline \multicolumn{4}{|c|}{ Use case 8: UCs:SLM:SLA:EWR Early Warning Notification to GI } \\
\hline Maturity level Requirements Passed & $\begin{array}{l}\text { Total } \\
\text { requirements }\end{array}$ & $\begin{array}{l}\% \text { Complete for } \\
\text { maturity level }\end{array}$ & \multirow{2}{*}{$\begin{array}{l}\text { Maturity level } \\
\text { Level } 1\end{array}$} \\
\hline Level 1" & 3 & 30100 & \\
\hline Level $2^{\prime}$ & $1^{r}$ & $1 \odot$ & Level 2 \\
\hline Level $3^{r}$ & $2^{\prime}$ & 3 (1) 66.6666667 & Level 3 \\
\hline Level 4 & $0^{\prime}$ & $3 Q$ & Level 4 \\
\hline Level $5^{r}$ & $0>$ & $3 Q$ & Level 5 \\
\hline
\end{tabular}

Figure 8-Quick wins in harmonising use case maturity levels 


\subsection{Long-term view}

As seen above, the assessment results quickly catalysed short and longer-term discussion of the ITSM plans and priorities for PL-Grid. These were developed in discussion with gSLM to allow for future planning.

First, the exercise reconfirmed why PL-Grid and the Polish Grid community is interested in ITSM. Their users expect a commercial quality of service and over the past years they have become aware that providing this implies some level of formal service management. Equally, from their point of view, resource managers at sites they federate want to have detailed information on users plans to allow resources to be used in the most efficient way possible. PL-Grid are seeking to build an equal relationship with users, codifying mutual responsibilities, addressing user needs, expectations and problems in a professional way that grows user satisfaction and efficiently uses available resources.

In terms of strategy, PL-Grid aims to use the assessment results to improve poorly performing areas to a more consistent standard rather than pushing already reasonably mature use cases to higher levels. This is both to be able to present a consistent level of service and also because the low performing use cases are concerning to management.

Shorter-term plans are to address use cases 7 and 8, discussed above. This is both because they present relatively quick wins, and also because it is important for PL-Grid to control access to the resources they federate. Use cases 7 and 8 cover noticing and alerting stakeholders to OLA violations, so cases where agreements between the Grid Infrastructure and sites is broken by one or other party. Following on from that, being able to predict possible future OLA violations is important in terms of securing resources.

\subsection{Tool feedback}

Following the assessment, PL-Grid and gSLM discussed the experience of PL-Grid in collecting and analysing the data. While both groups agreed the experience was largely positive, there were some issues with the survey. These were caused by three main factors. The first was the terminology used. Despite efforts by gSLM, there is still a terminology gap between the Grid and ITSM communities. The gSLM project provides a Glossary of terms [9], which may alleviate this problem to some extent, but it is probably also advisable to check on the terminology used for the next version of the survey.

Another issue noted by PL-Grid was that some questions were unclear in places, as they came from a context (connected to use case maturity) that was absent when presented as a plain list of questions. As a result for future surveys more context on requirement questions should be provided. Finally an issue was noted with the number of questions. With 181 requirements only from the SLM use cases, a large amount of time is necessary to provided the requested data, and this problem will only be exacerbated when a survey that also includes Service Delivery Management related use cases is available. A possible solution for future surveys is to allow users to provide data only for use cases of interest to the Grid Infrastructure. This would give a smaller subset of questions that could be answered to reduce the effort needed from participants.

All these factors will be taken into account when updating the assessment systems. 


\section{Conclusions}

Here we explain some of the background of Grid Infrastructures and how, due to their academic background, they developed with relatively little formal service level management, except for valuable but relatively technically focussed solutions. We demonstrate that there are other, organisational and managerial aspects of service management, which will be necessary for Grid and other federated infrastructures as they mature and wish to be compared with or compete with commercial services like Clouds. These topics are increasingly of interest to Grid Infrastructures, which has led to the gSLM project and also to the interest in engaging with the project from various community members. While existing commercial standards like ISO/IEC 20000 and frameworks like ITIL cannot be adopted wholesale, by interpreting them in a way comprehensible to Grid practitioners it is possible for the federated infrastructure community to benefit from them. This reinterpretation requires, amongst other things, a mix of new terminology and presenting change as an incremental rather than revolutionary process.

We have presented a simplified actor model of Grid Infrastructures that imposes enough order for modified versions of commercial ITSM techniques to be implemented. Furthermore we have presented a use case model, which reduces the service management relation activities in a Grid Infrastructure into a finite number of actions. These also allow the construction of a maturity model, describing the state of an infrastructure at various maturity levels across each use case, which itself allows construction of a database of maturity requirements based on these use cases and maturity levels.

This combination of models allows the construction of a requirements-based analysis system for Grid Infrastructures. By answering a list of questions related to the requirements, we can provide the infrastructures maturity level across each use case. We used this assessment tool on PL-Grid, the Polish National Grid Infrastructure, as both a validation of the assessment framework and to test and improve the online tools used for the assessment. Here we present results based on initial analysis, examining priority and relevance of use cases, seeking 'quick wins' and discussing long-term strategy. This approach shows that the assessment tool provides interesting information, which has value on its own but can also serve as a basis for more in-depth consultancy and discussion. In the context of PLGrid, we were able to begin this process, though it should and will continue for them to get the maximum benefit from the exercise. However, initial results are positive in that they match the anecdotal maturity level of the infrastructure but have also provided PL-Grid new information, which they are using to plan improvements to their service management. This is an effective validation of the assessment framework. While work is needed on the assessment tool and in refining the assessment questions, these can be carried out in the context of adding the second stage, Service Delivery Management related use cases. This input will be taken by the gSLM project in updating their tool, and will also feed into a strategic roadmap on service management in Grids and federated infrastructures to be released later this year. 


\section{Annex: Use cases and examples of maturity levels and requirements}

This section gives examples of the systems and structures in the gSLM model described in the paper. Table 1 lists the Use Cases developed.

Table 1 - List of gSLM Use cases

\begin{tabular}{|c|c|c|}
\hline Level & Area & Name \\
\hline \multirow{16}{*}{ 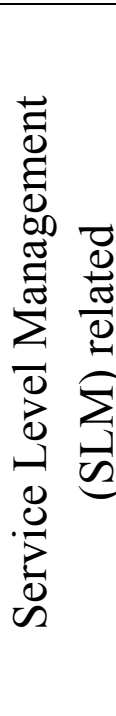 } & \multirow{8}{*}{$\begin{array}{l}\text { Service Level } \\
\text { Agreement } \\
\text { (SLA) related }\end{array}$} & Register new VO as "customer" of a GI \\
\hline & & Request a new service \\
\hline & & Publish service / add service to service catalogue \\
\hline & & Negotiate and sign SLA \\
\hline & & Monitor SLA fulfilment through the GI \\
\hline & & Evaluate and report on SLA fulfilment \\
\hline & & Notify VO of SLA violation \\
\hline & & Early warning notification to GI \\
\hline & \multirow{8}{*}{$\begin{array}{l}\text { Operational } \\
\text { Level } \\
\text { Agreement } \\
\text { (OLA) related }\end{array}$} & Register new Site as resource provider within a GI \\
\hline & & Register new GI as member of a higher level GI \\
\hline & & Register new service element / instance / component to GI \\
\hline & & Negotiate and sign OLA \\
\hline & & Monitor OLA fulfilment \\
\hline & & Evaluate and report on OLA fulfilment \\
\hline & & Notify site or lower level GI on OLA violation \\
\hline & & Early warning notification to GI or higher level GI \\
\hline \multirow{21}{*}{ 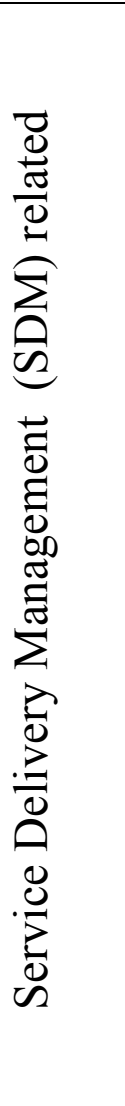 } & \multirow{4}{*}{$\begin{array}{l}\text { Continuity/ } \\
\text { Availability- } \\
\text { related }\end{array}$} & GI creates, maintains and enforces a Grid-wide continuity and availability plan \\
\hline & & GI monitors availability of Grid services \\
\hline & & GI manages availability- and continuity-related risks \\
\hline & & GI plans, implements and reviews disaster mitigation and contingency controls \\
\hline & \multirow{2}{*}{$\begin{array}{l}\text { Capacity- } \\
\text { related }\end{array}$} & GI maintains a Grid-wide capacity plan \\
\hline & & GI monitors performance and workload of Grid services and resources \\
\hline & \multirow{3}{*}{$\begin{array}{l}\text { Security- } \\
\text { related }\end{array}$} & GI maintains and enforces a Grid-wide security policy \\
\hline & & GI manages information security risks \\
\hline & & GI plans, implements and reviews security controls \\
\hline & $\begin{array}{c}\text { Configuration- } \\
\text { related }\end{array}$ & GI maintains configuration information \\
\hline & \multirow{5}{*}{$\begin{array}{l}\text { Change/ } \\
\text { Release/ } \\
\text { Deployment- } \\
\text { related }\end{array}$} & $\begin{array}{l}\text { GI maintains a Grid-wide change and release schedule (forward schedule of } \\
\text { changes) }\end{array}$ \\
\hline & & GI maintains a Grid-wide change and release policy \\
\hline & & GI agrees on standard change procedures with relevant actors \\
\hline & & GI notifies relevant actors of a future or completed change or release \\
\hline & & GI approves and coordinates non-standard change \\
\hline & \multirow{6}{*}{$\begin{array}{l}\text { Incident/ } \\
\text { Problem- } \\
\text { related }\end{array}$} & Incident is reported to GI \\
\hline & & GI agrees on standard incident handling procedures with relevant actors \\
\hline & & GI notifies relevant actors of an effective or resolved incident \\
\hline & & GI coordinates non-standard incident resolution \\
\hline & & GI identifies a problem \\
\hline & & GI coordinates problem resolution \\
\hline
\end{tabular}


Table 2 shows an example use case, and the kind of data that they comprise.

Table 2 - Use Case basic data example

\begin{tabular}{|c|c|}
\hline \multicolumn{2}{|r|}{ Basic data } \\
\hline Editor & Thomas Schaaf \\
\hline Use Case & UCs:SLM:SLA:REG \\
\hline Identifier & \\
\hline Use Case name & Register new VO as "customer" of a GI \\
\hline Scope & Service Level Management, Service Level Agreement (SLA) related \\
\hline $\begin{array}{l}\text { Informal } \\
\text { definition \& } \\
\text { example }\end{array}$ & $\begin{array}{l}\text { A Virtual Organization is recognized as a customer by the Grid Initiative (GI). } \\
\text { Typically, the VO will send a request via e-mail or web form to the GI. The GI } \\
\text { needs to validate the communication channel with the VO and identify the } \\
\text { representative(s) of the VO. The GI has to decide on whether the VO can be } \\
\text { accepted and registered. The GI might require the VO to accept certain general } \\
\text { rules and policies. The registration of a VO does not imply subscription or } \\
\text { invocation of one or more specific services delivered through the Grid at this point } \\
\text { in time. }\end{array}$ \\
\hline Pre-conditions & $\begin{array}{l}\text { - An existing Virtual Organization (VO) is interested in using Grid services } \\
\text { A Grid Initiative (GI) is coordinating the activities of a Grid offering } \\
\text { resources as a service to their so far registered VOs } \\
\text { The GI is empowered to register new VOs and negotiate and close SLAs } \\
\text { with them }\end{array}$ \\
\hline $\begin{array}{l}\text { Success end } \\
\text { condition }\end{array}$ & $\begin{array}{l}\text { The VO has been registered by the GI. To this end, relevant information about the } \\
\text { VO have been recorded by the GI. For example, a record has been created and } \\
\text { added to a database reflecting the GI's VO register. }\end{array}$ \\
\hline $\begin{array}{l}\text { Failed end } \\
\text { condition }\end{array}$ & $\begin{array}{l}\text { The VO has not been registered by the GI. The VO has been informed about the } \\
\text { reasons of the rejection of their registration request. }\end{array}$ \\
\hline Primary actors & VO, GI \\
\hline $\begin{array}{l}\text { Secondary } \\
\text { actors }\end{array}$ & The registration process does not involve any other actors than the primary actors. \\
\hline Trigger & $\begin{array}{l}\text { This use case is usually triggered by the VO that wants to register. The trigger is a } \\
\text { registration request by the respective VO. }\end{array}$ \\
\hline
\end{tabular}

Table 3 shows the maturity model for the same Use Case seen in Table 2.

Table 3 - Example of Maturity Model for a single Use Case

\begin{tabular}{|l|l|}
\hline \multicolumn{2}{|c|}{ Maturity Model: UCs:SLM:SLA:REG - Register new VO as "customer" of a GI } \\
\hline Level & Description \\
\hline $\begin{array}{l}\text { 0 Non- } \\
\text { existent }\end{array}$ & $\begin{array}{l}\text { There is no awareness for the need of a (formal) VO registration procedure. VOs are } \\
\text { not regarded as customers receiving value from the Grid. }\end{array}$ \\
\hline $\mathbf{1}$ Initial/Ad \\
hoc & $\begin{array}{l}\text { It has been recognized that a (formal) VO registration procedure should be in place. } \\
\text { But actual practices for registering new VOs vary and do not follow a defined } \\
\text { process. It is likely that the result of different steps performed during this use case } \\
\text { depend on the individuals involved. From the VO perspective, defined ways of } \\
\text { submitting their request do not exist and/or are not clearly communicated. There is } \\
\text { only poor documentation (records) of the actual actions performed. }\end{array}$ \\
\hline $\begin{array}{l}\text { Repeatable } \\
\text { (but }\end{array}$ & $\begin{array}{l}\text { There is an informal process for handling VO registration requests, which most of the } \\
\text { actions performed in the context of this use case follow. Most VOs know how to } \\
\text { submit a registration request to the GI. However, the process is unstructured, } \\
\text { rudimentary and prone to error. Pre-defined formal criteria for the evaluation of }\end{array}$ \\
\hline
\end{tabular}




\begin{tabular}{|l|l|}
\hline intuitive) & registration requests do not exist. \\
\hline 3 Defined & $\begin{array}{l}\text { There is a defined and documented process for handling VO registration requests in } \\
\text { place, including approval VO representative's identity and authorisation as well as } \\
\text { formal compliance checks of the VO registration requests and evaluation against pre- } \\
\text { defined criteria. However, errors occur, and sometimes the process is bypassed. Roles } \\
\text { and responsibilities are clearly defined, and people involved are mostly aware of their } \\
\text { duties. Interfaces between VOs and the GI include communication channels for } \\
\text { submitting and responding to registration requests and are sufficiently supported by } \\
\text { adequate tools/automation. A complete VO register is in place. }\end{array}$ \\
\hline $\begin{array}{l}\text { 4 Managed } \\
\text { and }\end{array}$ & $\begin{array}{l}\text { The process for handling VO registration requests is well developed and consistently } \\
\text { followed for all registration requests. There are only minimal exceptions. The process } \\
\text { is effective and efficient, but is not fully automated. At some points, it suffers from } \\
\text { lacks of organizational or technological integration, like, e.g. the submission form not } \\
\text { being fully integrated with CMDB. All actions performed are fully tracked, and all } \\
\text { registration requests and responses recorded in a history. The VO register itself is } \\
\text { fully developed and supportive to the entire process. The process is monitored for } \\
\text { quality, performance and exceptions. This includes monitoring and reporting of } \\
\text { metrics (performance indicators) like the average amount of time required to respond } \\
\text { to or complete a registration request. }\end{array}$ \\
\hline 5 Optimised & $\begin{array}{l}\text { Registration of VOs supports a wider plan for global service improvement and is } \\
\text { integrated into other tools and systems. As such VO registration is automated and } \\
\text { does not require manual intervention in all but exceptional cases. This generates a } \\
\text { VO register, which can be used not only to track user groups for an infrastructure but } \\
\text { to mine the data to allow optimisation of this and other processes. }\end{array}$ \\
\hline
\end{tabular}

Table 4 shows two examples of requirements that are generated from one level of the use case maturity model seen in table 3 .

Table 4-Requirements for a specific Use Case maturity level

\begin{tabular}{|c|c|c|c|c|c|c|}
\hline \multicolumn{7}{|c|}{ Requirements - UCs:SLM:SLA:REG Level 1 - Initial/ Ad hoc } \\
\hline ID & Use Case & SLM:SLA:REG & Maturity & L1 & Subject & GI \\
\hline \multirow{3}{*}{$\begin{array}{l}\text { Reqs: } \\
\text { SLM:SLA:REG:L1:1 }\end{array}$} & Title & \multicolumn{5}{|c|}{ Availability of contact data of GI } \\
\hline & Description & \multicolumn{5}{|c|}{$\begin{array}{l}\text { Basic communication means telephone number, e-mail, } \\
\text { and name of the contact person at GI. }\end{array}$} \\
\hline & Dependencies & \multicolumn{5}{|l|}{ None } \\
\hline ID & Use Case & SLM:SLA:REG & Maturity & L1 & Subject & GI \\
\hline \multirow{3}{*}{$\begin{array}{l}\text { Reqs: } \\
\text { SLM:SLA:REG:L1:2 }\end{array}$} & Title & \multicolumn{5}{|c|}{ Availability of means of recording contacts to $\mathrm{VO}$} \\
\hline & Description & \multicolumn{5}{|c|}{$\begin{array}{l}\text { Basic storage means for keeping telephone number, e- } \\
\text { mail, name of the contact person and other data to VO. } \\
\text { This storage is available at least for GI contact person. }\end{array}$} \\
\hline & Dependencies & \multicolumn{5}{|l|}{ None. } \\
\hline
\end{tabular}

\section{References}

[1] Service Delivery and Service Level Management in Grid Infrastructures (gSLM) is a project cofunded under the seventh framework programme, contract number 261547. 
[2] Szepieniec, T., Kocot, J., Schaaf, T., Appleton, O., Heikkurinen, M., Belloum, A.S.Z, SerratFernández, J., Metzker, M., On Importance of Service Level Management in Grids. In: Alexander, M., D'Ambra, P., Belloum, A., Bosilca, G., Cannataro, M., Danelutto, M., Di Martino, B., Gerndt, M., Jeannot, E., Namyst, R., Roman, J., Scott, S. L., Träff, J. L., Vallée, G., Weidendorfer, J., (Eds.): Euro-Par 2011: Parallel Processing Workshops - CCPI, CGWS, HeteroPar, HiBB, HPCVirt, HPPC, HPSS, MDGS, ProPer, Resilience, UCHPC, VHPC, Bordeaux, France, August 29 September 2, 2011, Revised Selected Papers, Part II. Lecture Notes in Computer Science 7156 Springer 2012, ISBN 978-3-642-29739-7

[3] Chronz, P., Wieder, P., Integrating WS-Agreement with a framework for service-oriented infrastructures. 225-232 in Proceedings of the 2010 11th IEEE/ACM International Conference on Grid Computing, Brussels, Belgium, October 25-29, 2010. IEEE 2010, ISBN 978-1-4244-9348-7

[4] Battré, D., Brazier, F. M. T, Clark, K. P., Oey, M. A., Papaspyrou, A., Wäldrich, O., Wieder, P., Ziegler, W., A proposal for WS-Agreement Negotiation. 233-241 in Proceedings of the 201011 th IEEE/ACM International Conference on Grid Computing, Brussels, Belgium, October 25-29, 2010. IEEE 2010, ISBN 978-1-4244-9348-7

[5] Kearney, K. T., Torelli, F., Kotsokalis, C., SLA star: An abstract syntax for Service Level Agreements. 217-224 in Proceedings of the 2010 11th IEEE/ACM International Conference on Grid Computing, Brussels, Belgium, October 25-29, 2010. IEEE 2010, ISBN 978-1-4244-9348-7

[6] The five process maturity levels in the Capability Maturity Model, retrieved from http://en.wikipedia.org/wiki/File:Characteristics of Capability Maturity Model.svg 20-04-2012. Public domain license.

[7] The COBIT framework for IT management and governance is produced by ISACA, the Information Systems Audit and Control Association. See http://www.isaca.org (accessed 20-042012)

[8] See http://gslm.eu/wiki/index.php/Maturity_Model (accessed 27-07-2012).

[9] See http://gslm.eu/wiki/index.php/Glossary (accessed 20-04-2012).

[10]Radecki, M., Szepieniec, T., Szymocha, T., Szopa, M., Krakowian, M.,: Towards Professional Service Operations in Grids. In: Bubak M. (ed.) Building a National Distributed e-Infrastructure PL-Grid. LNCS, vol. 7136, pp. 27-39. Springer, Heidelberg (2012).

[11]Szepieniec, T., Tomanek, M., Radecki, M., Szopa, M. and Bubak, M.: Implementation of Service Level Management in PL-Grid Infrastructure. In: Bubak M. (ed.) Building a National Distributed e-Infrastructure - PL-Grid. LNCS, vol. 7136, pp. 171-181. Springer, Heidelberg (2012). 